\title{
Reflexiones didácticas para el análisis de los actos de habla descorteses en la red social Twitter
}

\section{Didactic reflections for the analysis of discourteous speech acts in the social network Twitter}

Recibido: 27 de septiembre de 2021 | Aprobado: 17 de noviembre de 2021

\section{Resumen}

El presente artículo tiene como objetivo analizar los fundamentos teóricos de la cortesía y descortesía verbal para proponer una reflexión didáctica que oriente el estudio de los actos de habla descorteses en la red social Twitter. La metodología empleada es de carácter cualitativo e incluye procesos de análisis y sistematización de los fundamentos teóricos referidos a la cortesía y descortesía verbal y su aplicación en el ámbito educativo. En definitiva, el estudio de este fenómeno lingüístico puede favorecer el desarrollo de la competencia pragmática de los usuarios de las redes sociales y, en especial, de los estudiantes universitarios. Además, el conocimiento que se puede adquirir con el estudio y aplicación de lo propuesto en este trabajo favorece la formación de ciudadanos más respetuosos y tolerantes.

Palabras clave: redes sociales; twitter; análisis del discurso; descortesía verbal; secuencia didáctica

\section{Abstract}

This article aims to analyze the theoretical foundations of verbal courtesy and discourtesy to propose a didactic reflections that guides the study of discourteous speech acts in the social network Twitter. The methodology used is qualitative in nature and includes processes of analysis and systematization of the theoretical foundations referring to verbal courtesy and discourtesy and their application in the educational field. It has been determined that the study of this linguistic phenomenon can favor the development of the pragmatic competence of users of social networks and, especially, of university students. In addition, the knowledge that can be acquired with the study and application of what is proposed in this work favors the formation of more respectful and tolerant citizens.

Keywords: social networks; twitter; discourse analysis; verbal impoliteness; didactic sequence

Profesor a medio tiempo del Departamento de Estudios Generales de la Pontificia Universidad Católica Madre y Maestra. Profesor titular de la Escuela de Letras de la Universidad Autónoma de Santo Domingo, imparte Letras Básicas y Morfología y Sintaxis. Para contactar al autor: fl.medina@ce.pucmm.edu.do

ISSN (en línea): 1814-4152 / Sitio web: http://cuaderno.pucmm.edu.do

CÓMO CITAR: Medina, F. (2022). Reflexiones didácticas para el análisis de los actos de habla descorteses en la red social Twitter. Cuaderno de Pedagogía Universitaria, 19 (37), 83-90. 


\section{Introducción}

La manera como las personas se comunican, regularmente, determina su respeto a las normas interaccionales que rigen el comportamiento de los miembros de una comunidad. Estas formas discursivas se estudian desde la pragmática lingüística y uno de los temas más trabajados desde esta área del saber es la cortesía y descortesía verbal (Brown y Levinson, 1987; Culpeper, 1996; Kerbrat-Orecchioni, 2004; Bravo, 1999, 2002, 2003, 2004, 2005, 2009, 2016, 2017; Kaul, 2017). Los seres humanos, como entes sociales, poseen una imagen social ${ }^{1}$ (Goffman, [1967]1970), la cual es resguardada mediante diversas estrategias verbales y no verbales porque de ella depende su valor social.

Los intercambios comunicativos presenciales y virtuales ponen en riesgo la integridad de la imagen social de las personas. Por esta razón, cuando alguien habla, cuida que sus enunciados sean lo más corteses y adecuados posible para que el destinatario no sienta amenazada su imagen social. Sin embargo, en muchas ocasiones, la intención de los hablantes es afectar a sus oyentes mediante su discurso. Este tipo de actos de habla ${ }^{2}$ se pueden clasificar como actos de descortesía verbal.

El desarrollo de las redes sociales de internet ha permitido la creación de comunidades virtuales donde los usuarios realizan actos de habla corteses y descorteses. Estos discursos han sido analizados en los trabajos de diferentes investigadores. En los siguientes párrafos se hace referencia a algunos de ellos:

Retana y Ficoseco (2021) analizaron los comentarios hechos a dos noticias de medios costarricenses colocadas en la red social Facebook. Los investigadores determinaron que las personas con poco dominio de la norma de la lengua escrita reciben mucha censura. Además, llegaron a la conclusión de que las expresiones descorteses más comunes son el insulto y el sarcasmo. En ese mismo orden, Molina et al. (2019) desarrollaron una investigación sobre los comentarios hechos a noticias electorales publicadas en Facebook. Con este trabajo, observó que la condescendencia, la crítica y los insultos fueron las estrategias discursivas que más utilizaron los usuarios. Los investigadores han llegado a la conclusión de que las personas que usan esta red social producen comentarios descorteses para afectar la imagen social de los demás.

De su parte, Gutiérrez (2021) analizó la relación que existe entre los emojis y la cortesía en el entorno de Whatsapp. El autor comprobó que el emoji se emplea de forma dinámica entre los usuarios de esta red social, lo cual está relacionado con el estado de ánimo de los hablantes y con las actividades de cortesía que estos realizan para proteger su imagen social. Leal (2021) estudió la adquisición pragmática discursiva en L2/LE. La autora determinó que una adquisición eficaz de la competencia pragmáticadiscursiva en L2/ELE puede favorecer el desarrollo de la competencia comunicativa intercultural crítica.

Las conclusiones de los trabajos citados muestran que el tema de la cortesía y descortesía verbal se puede analizar desde los discursos que se producen en los entornos virtuales y en los salones de clase. En tal sentido, con este artículo se busca responder la pregunta: ¿cómo estudiar, desde la universidad, estos fenómenos lingüísticos en las manifestaciones discursivas realizadas en Twitter? Esta pregunta se puede responder mediante el cumplimiento del siguiente objetivo: analizar los fundamentos teóricos de la cortesía y descortesía verbal para reflexionar sobre una secuencia didáctica que oriente el estudio de los actos de habla descorteses en la red social Twitter.

La presente investigación es de tipo cualitativa porque con ella se busca analizar, sistematizar y, posteriormente, aplicar la teoría estudiada en el ámbito educativo. El método planteado está compuesto por tres procedimientos: primero, se analizan los fundamentos teóricos sobre el fenómeno estudiado mediante la descomposición de sus elementos constitutivos (Echavarría et al., 2010); segundo, se ofrece la sistematización de

1 Toda persona posee una imagen social, la cual le define como ente social porque establece su valor ante el grupo. Ver más en Goffman ([1967]1970).

2 Los actos de habla son los enunciados que producen las personas para expresar acciones lingüísticas, entre otros, se pueden destacar las órdenes, las preguntas, las promesas, las afirmaciones, las negaciones. (Searle, 1969). 
los datos analizados a partir de la observación práctica desde afuera y se reflexiona (Osses et al., 2006, p. 119); y, tercero, se propone una posible aplicación práctica desde el salón de clase (Castillo y Cabrerizo, 2006).

Este artículo está compuesto por una introducción donde se contextualiza el tema que se va a desarrollar, se presentan algunos de los trabajos más recientes sobre cortesía y descortesía verbal y sobre redes sociales de internet, se explica el método que se ha empleado para su desarrollo y se expone su estructuración; luego, se realiza una fundamentación teórica basada en los postulados fundamentales de los investigadores más representativos de este fenómeno lingüístico; posteriormente, se explica la secuencia didáctica que se sugiere para el análisis de la descortesía verbal en la red social Twitter; y, finalmente, se presentan las conclusiones a las que se ha arribado y las perspectivas de futuro con relación al tema trabajado.

\section{Fundamentación teórica}

Las redes sociales de internet se han convertido en importantes instrumentos de comunicación (Pérez y Ficoseco, 2021). La creación de espacios como Twitter $^{3}$ ha permitido la manifestación generalizada de la opinión de las personas sobre diferentes tópicos sociales. Los ciudadanos, regularmente, "(...) buscan espacios para ejercer su derecho a participar en la política por medio de internet (...)" (Bohórquez et al., 2020, p. 186). Los internautas, también, utilizan estos entornos para compartir sus ideas sobre temas relacionados con el deporte, la salud, la tecnología, la educación, entre otros.

Todo hablante, incluyendo los de los espacios virtuales, dirige su discurso a un oyente o a un oyente potencial que cuenta con unas cualidades específicas ${ }^{4}$. Los receptores de los enunciados que se presentan en las redes sociales forman parte de una comunidad o auditorio virtual. Al igual que en otras comunidades; esta, también, se compone de sujetos discursivos que manifiestan puntos de vista diferentes y, por la naturaleza misma del espacio donde se produce la interacción, “(...) tienen derecho a interpretación y opinión, y a asumir el rol de destinatarios" (Bravo, 2016, p. 116).

En tal sentido, las redes sociales de internet representan una oportunidad de acercamiento comunicativo entre los ciudadanos; ya que, en estos espacios digitales, las personas publican opiniones, datos y archivos que favorecen la interacción (Bohórquez et al., 2020). Sin embargo, algunas de estas publicaciones pueden representar actos de habla que dañan la imagen social de algunos internautas y, posiblemente, las respuestas ofrecidas a estas publicaciones, dependiendo del tema tratado, pueden ser violentas y/o groseras (Cisneros y Díaz, 2020).

En las redes sociales de internet, más que en cualquier otro espacio, el cuidado de la imagen social es una tarea a la cual las personas dedican mucho tiempo (Bard y Magallanes, 2021). Tradicionalmente, la idea que se tiene del sintagma imagen social (face) se vincula al conjunto de virtudes que posee una persona, las cuales manifiesta, a través de sus acciones verbales y no verbales, para que la sociedad las aprecie y valore (Bernal, 2007). Por esta razón, el cuidado de la imagen social es de suma importancia. Además, cuando el hablante mantiene una imagen adecuada, goza de cierto prestigio ante los demás.

El concepto imagen social fue incorporado a la lingüística, específicamente a la pragmática, a partir de los trabajos de Erving Goffman ([1967]1970). Para este autor las personas participan en actos comunicativos que ponen en riesgo su imagen social y la de los demás. Goffman ([1967]1970) considera que la imagen social es "(...) el valor social positivo que una persona reclama para sí mismo por la línea que otros asumen que ha tomado durante un contacto en particular" (Goffman, [1967]1970, p.13). Su conservación está sujeta a la asimilación de las normas de interacción determinadas por el grupo social. Del mismo modo, Goffman ([1967]1970) plantea que:

3 "Es un canal de comunicación rápido entre una persona y una comunidad, que en el lenguaje de Twitter se denominan: seguidores o "followers" (Gómez y Torres, 2010, p. 539).

4 Al producir un enunciado, se busca un fin determinado. Por tal razón, se puede apuntar que los demás elementos de la enunciación (ámbito discursivo, género, tipo de texto o secuencia textual, locutor, interlocutor, imágenes de enunciador y enunciatario, registro y tonalidad) están al servicio de tal propósito (Martínez, 2002). 
Puede decirse que una persona tiene, o está en, o mantiene la cara cuando la línea que sigue efectivamente presenta de la persona una imagen que resulta interiormente coherente, respaldada por los juicios y las evidencias expresados por los otros participantes, y confirmada por las evidencias expresadas por medio de instrumentos impersonales de la situación (p. 14).

Brown y Levinson (1987), siguiendo las ideas de Goffman ([1967]1970), sostienen que la imagen social se compone por dos tipos de imágenes: la negativa y la positiva. La imagen negativa se define como el anhelo de actuar con libertad, es decir, la necesidad de hacer cosas, en un territorio determinado, sin que los demás lo impidan. La imagen positiva, por su parte, se entiende como el concepto que una persona tiene de sí mismo, es decir, la autodefinición que un hablante ha hecho de sí, la cual es proyectada por medio de sus actos verbales y no verbales a fin de que sus interlocutores la reconozcan y la acepten (Brown y Levinson, 1987, p. 61).

En este sentido, Kerbrat-Orecchioni (2004) plantea que tanto la imagen negativa como la imagen positiva se fundamentan en las ideas de territorio y guardar/perder la imagen de Goffman ([1967]1970):

Brown y Levinson extienden sensiblemente la noción incorporándole lo que Goffman llama el territorio (o más bien, los territorios del yo: territorio corporal, material, espacial, temporal, cognitivo ...), rebautizado imagen negativa para la circunstancia. En cuanto a la imagen, tal cual está conceptualizada en la lengua ordinaria (en particular en las expresiones guardar / perder la imagen), desde esta perspectiva pasa a ser la imagen positiva: no hay, pues, ninguna oposición entre las dos imágenes, sino, muy por lo contrario, se trata de dos componentes complementarios de la identidad social (p. 41).

La imagen negativa puede verse amenazada por tres tipos de actos de habla. El primer tipo consiste en la invitación a la realización de acciones futuras. Algunos ejemplos son las órdenes y solicitudes; las sugerencias y los consejos; los recordatorios y las amenazas, advertencias y atrevimientos. El segundo está compuesto por los actos donde se expresa algún bien o beneficio, el cual debe ser aceptado o rechazado, a saber: los ofrecimientos y las promesas. Por último, las expresiones donde se manifiesta interés por los bienes ajenos: cumplidos, expresiones de envidia o admiración y expresiones de odio, ira, lujuria, entre otros (Brown y Levinson, 1987, pp. 65-66).

Por su parte, la imagen positiva se ve expuesta cuando se realizan dos tipos de actos de habla. El primero se refiere a las críticas: expresiones de desaprobación, crítica, desprecio o burla; quejas, reprimendas, acusaciones, insultos, contradicciones y desafíos. El segundo abarca las expresiones donde no se toma en cuenta si la imagen del destinatario puede verse afectada: expresiones intimidatorias o vergonzosas; irreverencias, menciones inapropiadas al contexto; malas noticias; planteamiento de temáticas polémicas como la religión, la raza, la política, entre otras (Brown y Levinson, 1987, pp. 66-67).

Los sujetos discursivos digitales ${ }^{5}$ llevan a cabo actos de habla que, regularmente, amenazan la imagen social propia y, sobre todo, la de sus destinatarios. En ese sentido, Culpeper (1996, pp.356-357) enlista algunas de las estrategias que emplean los hablantes para tales fines: a) descortesía abierta (bald on record impoliteness): actos de habla que expresan descortesía de manera abierta; b) descortesía positiva (positive impoliteness): enunciados que buscan dañar la imagen positiva del oyente mediante desvalorizaciones; c) descortesía negativa (negative impoliteness): expresiones que tiene como propósito perjudicar la imagen negativa a través de órdenes o mandatos; d) sarcasmo o burla (sarcasm or mock politeness): actos de habla que expresan lo contrario de una realidad con la finalidad de burlarse del destinatario; e) cortesía retenida (withhold politeness): intercambios comunicativos donde uno de los participantes nunca recibe una respuesta cortés, aunque el contexto así lo exige. Los siguientes enunciados representan ejemplos de las estrategias de descortesía descritas anteriormente: 1- Cierra la boca, nadie te dio permiso para hablar (descortesía abierta); 2- No eres capaz de interpretar mis ideas (descortesía positiva); 3- Borra ese comentario (descortesía negativa); 4- Ni un lingüística escribe con tanta corrección (sarcasmo o burla); 5- A pesar de todo, no debí decir eso de tu persona (cortesía retenida). Los enunciados 1, 2 y 3 sirven, además, para ejemplificar los actos que amenazan la imagen 
positiva y la imagen negativa descritas más arriba por Brown y Levinson (1987).

A partir de estas ideas, se deduce que la descortesía verbal se manifiesta mediante un comportamiento discursivo violento:

La descortesía verbal es una conducta que introduce agresividad en las relaciones sociales y los actos de habla que la plasman (primordialmente insulto, crítica, agravio, reproche, sarcasmo, burla, advertencia, invectiva, acusación, descalificación, amenaza, reprobación, provocación) conllevan la manifestación de fuertes emociones negativas tanto en quien produce el acto descortés como en quien lo recibe (principalmente ira, agresividad, rencor, antipatía, aversión) (Kaul, 2017, p. 7).

\section{Propuesta didáctica}

La propuesta didáctica que se presenta a continuación, se fundamenta en la metodología Aprendizaje Orientado en Proyectos (AOP). El AOP se puede definir como una estrategia didáctica que favorece el desarrollo de la cooperación, motivación, creatividad, resolución de problemas, entre otros; además, su puesta en práctica permite al estudiante desarrollar habilidades como la búsqueda de información y la utilización de las redes sociales de internet (Zepeda et al., 2019). De acuerdo a Buck Institute for Education (2013), esta metodología ofrece a los alumnos un contexto real de aprendizaje y, además, favorece su integración directa en los procesos pedagógicos planteados por el docente.

Por otra parte, las categorías de análisis que se han considerado para esta propuesta son los actos que perjudican la imagen social de las personas. Como se verifica en el cuadro I, se ha hecho hincapié en las estrategias directas y abiertas (Brown y Levinson, 1987, p. 60, 69) y en las estrategias de descortesía abierta y descortesía positiva (Culpeper, 1996, pp. 356-357). Por razones metodológicas se han combinado las estrategias directas y abiertas de Brown y Levinson (1987) con la descortesía abierta de Culpeper (1996), debido a que estas presentan importantes coincidencias. Esta unión se ha denominado descortesía abierta y directa (ver cuadro I). Se ha diseñado la siguiente consigna educativa para orientar la secuencia didactica que se propone a los estudiantes universitarios que cursan asignaturas relacionadas con la lingüística:

\section{Pontificia Universidad Católica Madre y Maestra Departamento de Estudios Generales}

\section{Español II}

\section{Prof. Faustino Medina}

La empresa de análisis de mercado donde laboras ha convocado a un grupo de empleados, incluyéndote, para el desarrollo de un proyecto. Se trata del análisis e interpretación de los actos de habla descorteses que dañan la imagen social de los usuarios de la red social Twitter. Para la realización de esta tarea, la compañía ha descrito los siguientes pasos:

1. Realización de reunión inicial para la distribución de tareas y el calendario de reuniones de seguimiento.

2. Identificación y lectura de autores que hayan realizado estudios sobre la descortesía verbal y sobre la manifestación de esta en las redes sociales.

3. Exploración de la red social Twitter y realización de búsqueda de términos que se consideren descorteses. Esta exploración servirá como punto de partida porque facilitará la identificación de los actos de habla descorteses.

4. Determinación y explicación de las características de los hablantes que serán tomados como muestra y el rango temporal que se ha establecido para analizar el fenómeno que se estudia. Por ejemplo: Para este análisis se han considerado cuarenta tuits: veinte de hablantes femeninos y veinte de hablantes masculinos. Además, los actos de habla seleccionados fueron emitidos entre los meses febrero y mayo del año 2021.

5. Selección de dos o tres categorías de análisis vinculadas a la descortesía verbal. Se recomienda tomar en cuenta las propuestas en la siguiente tabla:

5 Se refiere a los usuarios de redes sociales que realizan actos de habla mediante diferentes formatos como los textos, las imágenes, los videos y los emojis. 


\section{Tabla 1:}

Categorías y subcategorías a considerar en el análisis

\begin{tabular}{|c|c|}
\hline \multicolumn{2}{|c|}{ Categorías de análisis } \\
\hline $\begin{array}{l}\text { Descortesía abierta y directa } \\
\text { (Brown y Levinson, 1987, p. 60,69) } \\
\text { (Culpeper, 1996, pp.356-357) }\end{array}$ & $\begin{array}{c}\text { Descortesía positiva } \\
\text { (Culpeper, 1996, pp.356-357) }\end{array}$ \\
\hline $\begin{array}{c}\text { - Expresiones directas o } \\
\text { disfemismos } \\
\text { - Enunciados agresivos } \\
\text { • Amenazas } \\
\text { - Expresiones prosaicas } \\
\text { - Preguntas sarcásticas }\end{array}$ & $\begin{array}{c}\text { - Desaprobación y rechazo } \\
\text { - Imágenes de desaprobación } \\
\text { - Acusaciones directas } \\
\text { - Descalificaciones } \\
\text { - Preguntas acusadoras } \\
\text { - Agradecimiento irónico }\end{array}$ \\
\hline Subcategoría & de análisis \\
\hline
\end{tabular}

6. Utilización de la opción búsqueda avanzada disponible en la red social Twitter. Con esta opción se puede delimitar el resultado usando los siguientes filtros: palabra, frases exactas, cualquiera de esas palabras, cuentas, idioma y fechas.

7. Creación de corpus lingüístico mediante un conteo de las expresiones descorteses y clasificarlas según las categorías de análisis seleccionadas. Para tales fines se recomienda la utilización del siguiente cuadro:

\section{Tabla 2:}

\section{Conteo de expresiones descorteses}

Conteo de las expresiones descorteses

Expresiones empleadas

Categorías de análisis a la que pertenece

8. Análisis de las palabras y expresiones descorteses tomando en cuenta el contexto situacional donde se produjeron.

9. Redacción y presentación de informe final donde expongan y reflexionen en torno a

los datos encontrados. Este texto estará compuesto por una introducción, un desarrollo y una conclusión. La introducción y la conclusión serán de un párrafo de tres o más oraciones y el desarrollo contará con tres o cuatro párrafos de la misma cantidad de oraciones.

La aprobación de este proyecto estará sujeta al cumplimiento de los criterios planteados en la siguiente lista:

1. La presentación y explicación del informe final muestra que el trabajo fue desarrollado siguiendo todos los pasos sugeridos (2 puntos).

2. La entrega y presentación del informe demuestra que el trabajo se ha realizado con la colaboración de todos los miembros del equipo (1 punto).

3. El informe está compuesto por una introducción, un desarrollo y una conclusión, cada parte con la cantidad de oraciones solicitadas (2 puntos).

4. Se identifican, analizan y explican los actos de habla descorteses producidos por los usuarios de la red social Twitter (5 puntos).

5. Se ha realizado una redacción coherente y bien cohesionada (2 puntos)

6. El informe está redactado cuidadosamente y no presenta errores ortográficos (3 puntos).

\section{Conclusión}

Como se ha planteado, los actos de habla descorteses también se realizan en las redes sociales de internet. Su estudio permite, entre otras cosas, la adquisición y desarrollo de la competencia pragmática en los usuarios de las redes sociales y, en este caso, en los estudiantes universitarios. Los docentes de lengua y literatura pueden aprovechar las manifestaciones discursivas realizadas en estos espacios virtuales para estudiar y proponer a sus estudiantes el estudio de este y otros fenómenos lingüísticos. En tal sentido, se espera que los pasos propuestos en la consigna presentada sirvan para guiar un proceso para la realización de este tipo de investigaciones o en la sistematización de otros procedimientos para tales fines. Estos pasos son 
flexibles y, por lo tanto, admiten modificaciones parciales o totales.

El presente trabajo, además, puede favorecer la creación de una cultura de respeto y tolerancia frente a las opiniones de los demás, fuera y dentro de las redes sociales de internet. El estudio y reflexión del tema propuesto en esta investigación pudiera servir para que los usuarios de las redes sociales y, en especial, los estudiantes universitarios, reflexionen sobre el cuidado de su imagen social y, sobre todo, por el cuidado de la imagen social de los demás. Finalmente, se debe plantear que las ideas y procedimientos que se abordan en esta propuesta serán considerados por el autor para el desarrollo de futuras investigaciones en torno al análisis de la descortesía verbal dentro y fuera del salón de clase.

\section{Referencias bibliográficas}

Bard, G. y Magallanes, M. (2021). Instagram: La búsqueda de la felicidad desde la autopromoción de la imagen. Culturales, 9, 1-29. https://doi.org/10.22234/recu.20210901. e519

Bernal, M. (2007). Categorización sociopragmática de la cortesía y de la descortesía. Un estudio de la conversación coloquial española (Tesis doctoral). Universidad de Estocolmo, Estocolmo, Suecia.

Bohórquez, G., Flórez, J. y Alguero, M. (2020). Comunicación digital entre ediles y usuarios en Twitter: Oportunidad fallida en el fortalecimiento de imagen y vigencia en la esfera pública. ÁNFORA, 28(50), 183214. $\quad$ https://doi.org/10.30854/anf.v28. $\underline{\mathrm{n} 50.2021 .786}$

Bravo, D. (1999). ¿Imagen positiva vs. Imagen negativa?: pragmática sociocultural y componentes de face. Oralia: Análisis del discurso oral, (2), 155-184.

Bravo, D. (2002). Actos asertivos y cortesía: imagen del rol en el discurso de académicos argentinos. En Placencia, M.E. y Bravo, D. (eds). Actos de habla y cortesía en español (pp. 141-174). München: Lincolm Europa.
Bravo, D. (2003). Actividades de cortesía, imagen social y contextos socioculturales: una introducción. In La perspectiva no etnocentrista de la cortesía: identidad sociocultural de las comunidades hispanohablantes. Proceedings of the First Colloquium of EDICE Program (pp. 98-108). University of Stockholm.

Bravo, D. (2004). Tensión entre universalidad y relatividad en las teorías de la cortesía. En Pragmática sociocultural: estudios sobre el discurso de cortesía en español (pp. 15-38). Ariel.

Bravo, D. (2005). Categorías, tipologías y aplicaciones. Hacia una redefinición de la "cortesía comunicativa". En Bravo, D. (ed). Estudios de la (des)cortesía en español. Categorías conceptuales y aplicaciones a corpora orales y escritos (pp. 21-52). Editorial Dunken.

Bravo, D. (2009). Pragmática, sociopragmática y pragmática sociocultural del discurso de la cortesía. Una introducción. En Bravo, D., Hernández Flores, N. y Cordisco, A. (Eds.), Aportes pragmáticos, sociopragmáticos y socioculturales a los estudios de la cortesía en español (pp. 31-68). Dunken.

Bravo, D. (2016). Aplicaciones de la Pragmática Sociocultural. Actividades de imagen y expresiones de subjetividad en una entrevista de la BBC de Londres al presidente de Ecuador, Rafael Correa. En D. Dumitrescu, y D. Bravo, Roles situacionales, interculturalidad y multiculturalidad en encuentros en español (pp. 111-141). Buenos Aires: Dunken.

Bravo, D. (2017). Cortesía en español: negociación de face e identidad en discursos académicos. Textos en Proceso 3(1), pp. 49-127.

Brown, P. y Levinson, S. (1987). Politeness. Some universals in language usage. Cambridge: Cambridge University Press. 
Castillo, S. y Cabrerizo, J. (2006). Formación del profesorado en educación superior. Ed. Mac Graw Hill.

Cisneros, J. y Díaz, D. (2020). Escenas de violencia y discursos políticos en el Facebook. Centro Sur, 4(3), 1-31.

Culpeper, J. (1996). Towards an anatomy of impoliteness. Journal of Pragmatics, 25, 349367.

Echavarría, J., Gómez, C., Aristazábal, M. y Vanegas, J. (2010). El método analítico como método natural. Nómadas. Critical Journal of Social and Juridical Sciences, 25(1).

Goffman, E. ([1967]1970). Ritual de la interacción. Editorial Tiempo Contemporáneo.

Gómez, L. y Torres, C. (2010). Twitter. Colombian Journal of Anesthesiology, 38(4), 539 - 540. https://www.revcolanest.com.co/index.php/ rca/article/view/809

Gutiérrez, J. (2021). Emojis y cortesía: el caso del WhatsApp. Lengua y Sociedad, 20(1), 243259. http://revista.letras.unmsm.edu.pe/index.php/ls/article/view/2211

Searle, J. (1969). Actos de habla. Ediciones Cátedra SA.

Kaul, S. (2017). Tipos de descortesía verbal y emociones en contextos de cultura hispanohablante. Pragmática Sociocultural, 5(1), 119-123. doi: http://dx.doi.org/10.1515/ soprag-2017-0001

Kerbrat-Orecchioni, C. (2004). ¿Es universal la cortesía? En Bravo, D. y Briz, A. (eds.). Pragmática sociocultural: estudios sobre el discurso de cortesía en español, pp. 39-54. Barcelona: Ariel Lingüística.
Leal, N. (2021). Adquisición pragmática discursiva en L2/LE: marco conceptual y aplicativo para la educación superior. Espiral. Cuadernos del profesorado, 14(29), 8.

Martínez, M. (2002). Lectura y escritura de textos. Perspectivas teóricas y talleres. Universidad del Valle.

Molina, N., Vergara, A. y Quesada, E. (2019). Descortesía en comentarios de Facebook relativos a noticias electorales de CRHoy.com y La Nación durante el proceso electoral del 2018 en Costa Rica. Pragmalingüística, (27), 233-255. https://revistas.uca.es/index.php/ pragma/article/view/4789

Osses, S., Sánchez, I. e Ibáñez, F. (2006). Investigación cualitativa en educación: hacia la generación de teoría a través del proceso analítico. Estudios pedagógicos (Valdivia), 32(1), 119133.

Pérez, D. y Ficoseco, V. (2021). Violencia y descortesía en redes sociales. Káñina, 45(2), 161 184. https://doi.org/10.15517/rk.v45i2.47888

Retana, D. P. y Ficoseco, V. (2021). Violencia y descortesía en redes sociales. Káñina, 45(2), 161-184.

Zepeda, M., Cardoso, E. y Cortés, J. (2019). aprendizaje orientado en proyectos para el desarrollo de habilidades blandas en el nivel medio superior del IPN. Revista Iberoamericana para la Investigación y el Desarrollo Educativo, 10(19). 